\title{
Effects of anterior vs posterior cingulate lesions on passive-avoidance responding in rats
}

JOHN J. BOITANO, DEPARTMENT OF PSYCHOLOGY, FAIRFIELD UNIVERSITY, Fairfield, Connecticut, JOEL F. LUBAR, UNIVERSITY OF TENNESSEE, Knoxville, AND MARYANNE S. FURNALD, ROSARY HILL COLLEGE; Buffalo, N.Y.

Rats with posterior cingulate damage were statistically different from anterior cingulate $S$ s and controls in a discrete-trial passiveavoidance task. However, the extent of the debility did not parallel that usually seen after massive hippocampectomy. Both a safe-island test and a continuous-trial situation failed to distinguish between the groups.

Since McCleary's (1961) initial experiment demonstrating that removal of the mid-cingulate region in cats produces no deficit in passive-avoidance responding (PAR), a number of other studies have been performed and similar results have been found. For instance, Lubar's (1964) and Cornwell's (1966) cingulectomized cats were not deficient in withholding a previously acquired approach response to electrified food in a discrete-trial PAR situation. Kaada, Rasmussen, \& Kveim (1962) also reported no differences between rats with anterior, middle, and posterior cingulate destruction or controls in a continuous-trial PAR task. In the continuous-trial PAR task $S$ is allowed to respond for food or food plus shock for a predetermined period of time with entry to the food compartment always available.

It was the purpose of the present study to test the effects of anterior vs posterior cingulectomy in rats by extending PAR to include the discrete-trial situation, the safe-island procedure, and the continuous-trial test. It was hypothesized that (a) if the prevailing view of structural and functional uniformity with regards to the cingulate cortex was correct, and (b) if there was behavioral generality across specific passive-avoidance tests, then no significant differences would be expected between experimental and control Ss.

SUBJECTS, SURGICAL PROCEDURES, AND HISTOLOGY

The Ss were 20 male hooded rats weighing on the average between 300 and $350 \mathrm{~g}$ at the time of surgery. Six Ss received bilateral ablations of the anterior cingulate cortex, six sustained bilateral ablation of the posterior cingulate cortex, and eight served as controls. In this latter group, there were four sham operates and four unoperated normals. On the behavioral measures where the shams and normals were indistinguishable statistically, they were combined into the larger control group. All lesions were created by aspiration.

Histological examination of the brain sections stained with thionin revealed for the anterior cingulates bilateral tissue damage beginning at the most rostral extent of the midline overlying the olfactory bulb. This damage extended caudally and usually ended at the level of the septum just prior to the crossing of the anterior commissure. For the posterior group, the bilateral midline destruction began at the level of the septal area and continued caudally, ending in the region of the posterior hippocampus. Ancillary damage involved the corpus callosum, and in isolated instances the top layer of cells in the hippocampus (alveus) and the septum. Thalamic gliosis was noted in several.cases and was confined to $n$. ventralis thalami, $n$. ventralis anterior thalami, $n$. ventralis thalami pars dorsomedialis and $\mathrm{n}$. lateralis thalami. SAFE-ISLAND PAR

Each $S$ was placed on a small 6 in. square Masonite platform, positioned centrally 2.5 in. above a grid floor. Whenever $S$ left the platform and stepped on adjacent grid bars, a $1.0 \mathrm{~mA}$ ac foot-shock was received. Locomotor activity was measured by means of an ultrasonic activity device mounted on the side wall just above floor level. Testing in the presence of shock lasted $16 \mathrm{~min}$ with activity being monitored every $4 \mathrm{~min}$. One day later, the Ss were retested under exactly the same conditions but without shock.

Analysis of covariance (Winer, 1962) of the log-transformed retest scores which adjusted for the different mean performances during original testing revealed nonsignificant group differences for the latency of initial descent $(F=.49, \mathrm{df}=2 / 16, \mathrm{p}>.05)$ and for the total time spent on the platform $(F=1.34, \mathrm{df}=2 / 16, \mathrm{p}>$ $.05)$. In addition, gross locomotor activity failed to distinguish between the groups during original and final testing ( $F_{S}<1.48, \mathrm{df}$ $=2 / 16, \mathrm{p}>.05)$.

\section{CONTINUOUS-TRIAL PAR}

The apparatus and procedure were similar to that reported previously (Boitano \& Isaacson, 1967). Briefly, under $48 \mathrm{~h}$ of water deprivation, Ss were placed in a large copper-bottomed box and allowed to freely explore for $16 \mathrm{~min}$. At the end of this adaptation period, they were removed, an electrified water dish was inserted, and the $\mathrm{Ss}$ were replaced for another $16 \mathrm{~min}$. The number of self-administered mouth-shocks $(.27 \mathrm{~mA}$ ac) was automatically recorded. While there was a tendency for the anterior cingulates to accept more mouth-shocks than the posterior cingulates, a Mann-Whitney $U$ test revealed no group differences $(U=14, p=.59)$. Moreover, both cingulate groups were not statistically different from either the sham or normal control Ss. (Us $=6$ to $8, \mathrm{ps}=.26$ to .48 .)

\section{DISCRETE-TRIAL PAR}

Each $S$ was trained under $23 \mathrm{~h}$ of water deprivation to enter a smaller compartment within $30 \mathrm{sec}$ after a guillotine door was raised to obtain a large water reward (four drops). S was then lured back into a larger compartment by a smaller reward (one drop of water), and the guillotine door was lowered. Such a cycle constituted a trial with a $1 \mathrm{~min}$ inter-trial interval. Between the 35 th and 36 th trial (10 trials/day) a $.68 \mathrm{~mA}$ ac shock was administered for $15 \mathrm{sec}$ through the grid floor of the smaller compartment while $S$ was drinking. The major dependent variable was the latency of entering (with two feet) the smaller chamber on the remaining non-shock trials.

Figure 1 indicates that all groups declined gradually in entrance latency over the course of the first 35 training trials. After the administration of shock, the time to re-enter the smaller compartment increased dramatically for all groups (Trials 36 to 40 ). On the subsequent trials, the posterior cingulates exhibited faster re-entrance latencies than the other two groups. A trend analysis performed on the log-transformed mean scores of Blocks 8-12 revealed statistically significant differences across groups $(\mathrm{F}=$

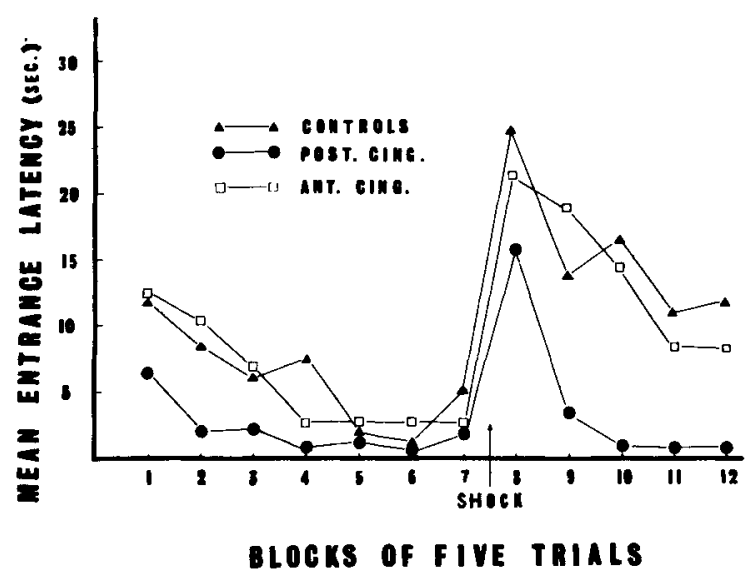

Fig. 1. Mean entrance latency (in sec) for the discrete-trial passiveavoidance problem. 
$4.79, \mathrm{df}=2 / 16, \mathrm{p}<.025)$ and trials $(\mathrm{F}=11.45, \mathrm{df}=4 / 64, \mathrm{p}<$ $.005)$.

\section{DISCUSSION}

The results indicate that the posterior cingulate $S$ s are deficient relative to the anterior cingulate group and control $S s$ in a passive-avoidance task involving conflict between shock and a learned approach-response but are not impaired on the other types of PAR. In addition to the differential sensitivity of each test in measuring selected aspects of PAR, there are a number of differences which may account for the essentially negative findings on the safe-island and continuous-trial tests. For example, the response to be withheld in the discrete-trial task involved many more preshock training trials than either of the other two tests. In addition, the conditions of motivation varied considerably over the three situations. In the discrete-trial task, the Ss were on $23 \mathrm{~h}$ of water deprivation for 11 consecutive days, including five days of adaptation. For the continuous-trial situation, the animals were deprived of water for $48 \mathrm{~h}$ while there was no deprivation imposed during the safe-island testing. Any or all of these factors may explain the observed discrepancies.

Aside from test differences, these findings suggest that the posterior median cortex of the rat functions differently than the anterior cingulate region in mediating response inhibition. The posterior area exerts a relatively greater influence than the anterior region. However, the contribution of the posterior cingulate cortex towards total response inhibition appears to be considerably less than the hippocampus insofar as massive hippocampectomy resulted in an immediate and lasting debility in the discrete-trial task (Isaacson \& Wickelgren, 1962). In the present study, the passive-avoidance impairment was not immediately apparent but developed gradually.

\section{REFERENCES}

BOITANO, J. J., \& ISAACSON, R. L. Effects of variation in shock-intensity on the behavior of dorsal-hippocampectomized rats in two passiveavoidance situations. Amer. J. Psychol, 1967, 80, 73-80.

CORNWELL, P. Behavioral effects of orbital and proreal lesions in cats. $J$. comp. physiol. Psychol, 1966, 61, 50-58.

ISAACSON, R. L., \& WICKELGREN, W. O. Hippocampal ablation and passive-avoidance. Science, 1962, 138, 1104-1106.

KAADA, B. R., RASMUSSEN, F. W., \& KVEIM, O. Impaired acquisition of passive-avoidance behavior by subcallosal, septal, hypothalamic, and insular lesions in rats. J. comp. physiol. Psychol, 1962, 55, 661-670.

LUBAR, J. F. Effect of medial cortical lesions on the avoidance behavior of the cat. J. comp. physiol. Psychol, 1964, 58, 38-46.

McCLEARY, R. A. Response specificity in the behavioral effects of limbic system lesions in the cat. J. comp. physiol Psychol, 1961, 54, 605-613.

WINER, B. J. Statistical principles in experimental design. New York: McGraw-Hill, 1962. 